\title{
Email communication in project management: A bane or a blessing?
}

\begin{tabular}{|c|c|}
\hline \multicolumn{2}{|c|}{$\begin{array}{l}\text { Authors: } \\
\text { Marius C. Smit }{ }^{1} \text { (D) } \\
\text { Taryn J. Bond-Barnard }^{1} \\
\text { Herman Steyn } \\
\text { Inger Fabris-Rotelli }\end{array}$} \\
\hline \multicolumn{2}{|c|}{$\begin{array}{l}\text { Affiliations: } \\
{ }^{1} \text { Department of Engineering } \\
\text { and Technology } \\
\text { Management, University } \\
\text { of Pretoria, South Africa }\end{array}$} \\
\hline \multicolumn{2}{|c|}{$\begin{array}{l}{ }^{2} \text { Department of Statistics, } \\
\text { University of Pretoria, } \\
\text { South Africa }\end{array}$} \\
\hline \multicolumn{2}{|c|}{$\begin{array}{l}\text { Corresponding author: } \\
\text { Taryn Bond-Barnard, } \\
\text { taryn.barnard@up.ac.za }\end{array}$} \\
\hline \multicolumn{2}{|c|}{$\begin{array}{l}\text { Dates: } \\
\text { Received: } 15 \text { Dec. } 2016 \\
\text { Accepted: } 14 \text { Feb. } 2017 \\
\text { Published: } 11 \text { Aug. } 2017\end{array}$} \\
\hline \multicolumn{2}{|c|}{$\begin{array}{l}\text { How to cite this article: } \\
\text { Smit, M.C., Bond-Barnard, } \\
\text { T.J., Steyn, H. \& Fabris-Rotelli, } \\
\text { I., 2017, 'Email } \\
\text { communication in project } \\
\text { management: A bane or a } \\
\text { blessing?', South African } \\
\text { Journal of Information } \\
\text { Management 19(1), a826. } \\
\text { https://doi.org/10.4102/ } \\
\text { sajim.v19i1.826 }\end{array}$} \\
\hline \multicolumn{2}{|c|}{$\begin{array}{l}\text { Copyright: } \\
\text { (c) 2017. The Authors } \\
\text { Licensee: AOSIS. This } \\
\text { is licensed under the } \\
\text { Creative Commons } \\
\text { Attribution License. }\end{array}$} \\
\hline \multicolumn{2}{|l|}{ Read online: } \\
\hline 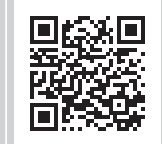 & $\begin{array}{l}\text { Scan this QR } \\
\text { code with your } \\
\text { smart phone or } \\
\text { mobile device } \\
\text { to read online. }\end{array}$ \\
\hline
\end{tabular}

Background: Project success used to be measured solely in terms of efficiency metrics such as scope, cost and time; however, there are proposals that more attention should be paid to process-related performance factors such as communication. The advent of email has significantly impacted the way the world communicates.

Objectives: This study investigates the preference of email communication relative to other communication mediums in project environments and the effect of email communication on feelings of stress and overload in the workplace.

Method: A survey with 430 responses was conducted to determine the communication preferences of project practitioners in a typical project. The average rank and frequency response methods were used to analyse the data.

Results: The findings indicate that the communication preferences of project practitioners still support the media richness theory and that face-to-face communication is the preferred communication medium in most situations. Despite email being disruptive and a cause of stress, the respondents did not indicate being overloaded because of email.

Conclusion: Even though there has been a dramatic shift towards email and electronic communication in projects, face-to-face communication is still the most preferred communication type for most situations. Furthermore, email is perceived as an effective tool to delegate, can be used to build and develop relationships and trust, and is an efficient and effective tool that contributes to project communication success.

\section{Introduction}

Project management and project management principles are increasingly applied in the execution of projects and other endeavours not previously managed as projects (Crawford \& Nahmias 2010). The narrow definition of project success as solely a function of efficiency metrics such as scope, cost and time is being challenged by authors who claim this to be a measure of project management success, rather than project success (Bryde \& Robinson 2005; Frodell, Josephson \& Lindahl 2008; Koops et al. 2016; Lim \& Mohamed 1999; McLeod, Doolin \& MacDonell 2012; Turner 2007). The importance of good communication to achieve success in projects is frequently outlined in the project management literature (Henderson, Stackman \& Lindekilde 2016; Lehmann 2009; Müller \& Turner 2001; Turner \& Müller 2004). Padalkar and Gopinath (2016) noted that there was a significant increase in project communication research between 2011 and 2015. However, the topic is still minimally represented in research in comparison to the other project management body of knowledge (PMBOK) knowledge areas. Literature suggests that it will become a more important topic in future as communication research is vital for investigating knowledge acquisition and assimilation in projects, which is a trending topic (Padalkar \& Gopinath 2016). This study investigates if practitioners' communication preferences are changing with the advent of the digital age, which contributes to a better understanding of how modern communication media impact practitioners and projects.

The advent of electronic mail (email) has significantly changed the way the world communicates and how communication media are defined. The immediacy of email and other electronic mail formats like text messaging is blurring the boundaries between synchronous and asynchronous media (Den Otter \& Emmitt 2007). More focus is being placed on more frequent, informal project updates via email while formal reports are gradually being restricted to high-level feedback (Bond-Barnard, Fletcher \& Steyn 2016).

The acceptance and use of email for conveying information that is both low and high in equivocality (this term is discussed later on in this paper) is greying the lines drawn by the 
theory of media richness and questions the measures used to define media richness. As project teams are often geographically dispersed, email is used to initiate and build relationships between project team members who will potentially never meet face-to-face (Cheshin et al. 2013). Email also has potential impediments because of its disruptive nature, opportunities for excessive delegation and its ability to overload users (Bawden \& Robinson 2009; Gantz, Boyd \& Dowling 2009; Sappelli et al. 2016). These impediments will be investigated in greater detail in this paper.

It is clear that communication is playing an increasingly important role in projects and project success (Ksenija \& Skendrovic 2010). Communication and the way that communication impacts projects are receiving more attention in academic research (Bond-Barnard et al. 2016; Henderson et al. 2016). The transformation of communication because of the arrival of new electronic communication media is noted, but the impact thereof on organisations is not clearly understood. Attempts have been made to govern email in organisations (PwC South Africa 2017). However, the use of email as a preferred communication medium in the workplace and in the project management environment is growing, but its impact on individual and project performance is not clearly understood. Researchers are still trying to pin down the characteristics of email by making use of previously accepted communication media frameworks. In the process, previously held beliefs about communication in the workplace and in projects are being challenged.

Given the changes in the perceived importance of communication in projects, and the uncertainty surrounding the characteristics and impacts of email communication in the work environment, an opportunity exists to study the use and impact of electronic messages on individuals in the project environment. This study explores communication preferences, describes how individuals manage their email and gauges the impact of email communication on individuals, their relationships, efficiency and effectiveness in the project environment. Six hypotheses are proposed: (1) email is replacing other types of media in the project management environment; (2) email is disruptive; (3) users experience stress and overload because of email; (4) email is an effective tool to delegate tasks; (5) email supports building relationships and trust; and (6) email creates conflict.

The study provides insight into communication preferences and the use of email communication in projects. The perceived 'disruptive' impediments of email communication as well as email's impact on individual and project performance are investigated in more detail. The findings contribute to a better understanding of how modern communication media impact practitioners and projects. This information is useful for practitioners and academics as they grapple to understand the role and the do's and don'ts of electronic communication in project environments.

\section{Literature review}

\section{The role of communication in projects}

Teams are formed to work on projects, and team members need to work together to ensure successful project completion. Among the various aspects of how team members should work together are issues regarding communication and, more specifically, communication regarding tasks and coordination (Chiocchio 2007).

The emphasis on communication as it applies to project management may be understood as part of two interrelated trends. Firstly, teams are used more frequently because of the requirement for tasks to be performed using complex systems and processes where it is difficult to achieve success without teamwork (Kahai, Sosik \& Avolio 2004 in Chiocchio 2007). This trend is related not only to globalisation and increased complexity but also to global and geographically dispersed project teams. Secondly, the way people communicate is modified by information technology such as email (Colquitt et al. 2002; Michinov, Michinov \& Toczek-Capelle 2004 in Chiocchio 2007).

\section{Communication and project success}

Cserháti and Szabó (2014), Ngai, Law and Wat (2008), Pinto and Slevin (1987) identified critical success factors (CSFs) for projects which can be used as an instrument for measuring project success. Among the factors that they identified were adequate communication channels. Similarly, Fortune and White (2006) reviewed 63 publications on CSFs to formulate a summarised list of CSFs. They also identified that good communication or feedback was one of 27 CSFs of a project.

Experts interested in transforming organisations and also project management maintain that a large number of projects can fail because of shortcomings or errors in communication (Elovitz 1999 in Lehmann 2009). Lehmann (2009) stated that project management must take communication phenomena into account; if not, the project may fail.

\section{Characteristics of communication mediums}

Media richness: The media richness theory, which builds on the social presence theory, argues that communication media differ in their ability to facilitate understanding. It is the media's 'information richness', defined as the amount of information a medium can convey to change the receiver's 'understanding within a time interval', that differentiates richer media from leaner media. The use of richer media leads to better performance for tasks with greater equivocality or ambiguity (Robert \& Dennis 2005).

Face-to-face communication is the richest medium and is preferred for highly equivocal tasks as it provides immediate feedback and allows that interpretation can be checked. Electronic media is generally believed to be leaner in richness and is preferred for non-equivocal tasks (Robert \& Dennis 2005). Researchers classify email as falling between telephonic 
communication and non-electronic written communication in terms of richness (Markus 1994; Robert \& Dennis 2005).

Mintzberg (1973) indicated that senior managers prefer verbal communication to written communication, mostly because of their need for a richer medium of communication. The need for richer media was attributed to the higher equivocality in the messages that they would generally convey.

If managers perceive email as higher in richness than the richness theory suggests, they might substitute email for some, possibly much of their telephonic communication. Media richness theory will therefore underestimate a manager's use of email to the extent that managers perceive email as higher in richness (Markus 1994).

Synchronous and asynchronous communication: Synchronous communication can be defined as direct communication where all parties involved in the communication are present at the same time. Synchronous communication includes face-to-face interactions such as meetings and informal discussions where the communication occurs at the same place and time. Moreover, electronic communication media such as video conferencing and instant messaging can also be viewed as synchronous communication; however, the communication in this instance occurs at different places at the same time (Den Otter \& Emmitt 2007). Asynchronous communication does not require that all parties involved in the communication be present at the same time, such as email messages and text messaging.

Email is both written and asynchronous, although with the speed of modern computer technology and the email habits of users it is becoming a more synchronous communication medium. According to Renaud, Ramsay and Hair (2006), email does not fit neatly into established categories or behave according to well-established asynchronous communication rules. They termed email as e-synchronous, as it is unlike either synchronous or asynchronous media.

Equivocality: The term 'equivocality' is used to describe communication tasks high in ambiguity, such as settling a dispute. Tasks high in equivocality require a communication medium that is rich in information, while tasks low in equivocality do not require this (Robert \& Dennis 2005). Different communication media vary in their ability to carry rich information. It is deemed to be important to match the richness of the medium with the equivocality of the communication task. Lean media lack adequate support for high equivocality tasks and may lead to miscommunication. The selection of the medium that matches the communication task leads to the most effective outcome.

The use of email for equivocal communication can largely be attributed to social behaviours that created richness by increasing the speed of email, rather than the capabilities of the medium itself (Markus 1994). The speed and convenience of email adds richness to the medium, which was previously associated with telephonic communication.

Multi-addressability: The ability to reach multiple persons simultaneously (multi-addressability) is a characteristic of both email and face-to-face communication, making it superior to telephonic communication. Multi-addressability results in individuals receiving more messages than they send, as email messages are often addressed to more than one recipient, or a number of recipients are included in the 'cc' field.

Multi-addressability can cause mistrust. Müller (2003) states that one-to-one communication is more informal and promotes trust and knowledge building. In contrast, one-tomany communication is more formal, creates mistrust and is controlled.

Another potential consequence of multi-addressability is the fact that email is not a collective means of communication, because senders choose to whom they send messages (Chiocchio 2007). As a result, team members can be kept out of the loop, intentionally or unintentionally.

\section{Formal versus informal communication}

Formal reports are perceived to be the most credible source of information (Johnson 1993 in Turner \& Müller [2004]). Mullins 1999 in Turner and Müller (2004) found that informal communication is perceived to be high in speed and low in accuracy, while formal communication is perceived to be low in speed but high in accuracy. Research by Johnson et al. 1994 in Turner and Müller (2004) supported this finding by stating that formal communication is more credible than informal communication.

Bond-Barnard, Steyn and Fabris-Rotelli (2013) found that a reduction in mistrust and conflict of interest can be achieved through a balance of frequent informal and formal communication. Their findings support Turner and Müller's (2004) research, which states that trust exists where informal communication is used.

\section{The application of email in organisations}

The explosion in the use of email by all levels in organisations, including senior management, for a multitude of tasks including tasks with high equivocality, would suggest that the richness of email according to the richness theory is wrong. Workers conduct much of their business via email, because it is perceived to be less time-consuming, more reliable and efficient than phoning or meeting face-to-face (Berghel 1997 in Renaud et al. [2006]). Email also maintains a durable record of requests or instructions, which is useful to resolve future disputes (Renaud et al. 2006).

The aspects of email that made it popular in the first place, that is, brevity and accessibility to superiors, seem to cause some problems once email become ubiquitous in business 
(Ramsay \& Renaud 2012). People use email exclusively, instead of direct interaction with other people (even in the same building), often to the detriment of the communication process. The traditional measures of communication effectiveness are being ignored in the interest of convenience and brevity.

\section{Email and relationships}

Email lacks the personal connection allowed by face-to-face and telephonic communication. Renaud et al. (2006) found that email is impoverished as compared to other media, and yet users seem to prefer it. Email lacks the contextual details because people find it laborious to replicate in a written format all that is conveyed through voice intonation and body language when they convey a message verbally (Cramton \& Orvis 2003 in Chiocchio [2007]). People, therefore, prefer to use telephonic communication to build and maintain relationships with people who are geographically dispersed. Markus (1994) interviewed several employees in his study that indicated that relationships with co-workers will become cold and impersonal if they communicated exclusively by email. It is appropriate and even necessary to use telephonic communication to prevent negative social outcomes and to maintain the personal connection. Frazee 1996 in Burgess, Jackson and Edwards (2005) highlighted the risk for misunderstanding and tension within the workplace because of ambiguous and poorly written email. Wilson (2002) stated that high-interaction participants found it frustrating to use email for developing relationships.

\section{Email overload and stress}

Whitaker and Sidner 1996 in Dredze, Blitzer and Pereira (2005) described the concept of 'email overload' and concluded that users performed a large variety of work-related tasks with email, and as a result, they are overwhelmed with the amount of information in their mailbox. Sumecki, Chipulu and Ojiako (2011) define email overload as the situation where possible business disruption because of email use may significantly harm the well-being of users and impair their productivity. The increase in workload attributable to email is one of the factors cited by Johnson et al. 2005 in Jerejian, Reid and Rees (2013) as contributing to office workers reporting the highest levels of stress in history.

Sproull and Kiesler 1991 in Renaud et al. (2006) attributed overload to the increased possibility and ease of making demands and requests of others. Mackay 1988 in Renaud et al. (2006) argued that the lower cost of delegating tasks to others increases the use of email. Worse than delegation by email, 'buck-passing' by means of email is bad work behaviour where work is dumped on a colleague by a sender without having faced him or her. Because the email is asynchronous, the person on which the work and associated responsibility is unexpectedly placed, often has no way of backing out (Ramsay \& Renaud 2012). Correlation research by Jerejian et al. (2013) indicated that the more email messages people handle, the more they perceive email as a source of stress. This study aims to determine if email is perceived to be an effective task delegation tool and if project practitioners experience stress and overload because of email.

\section{Email management}

Dabbish and Kraut (2006) found that a higher email volume was associated with increased feelings of email overload, but the relationship was moderated by certain email strategies. Their analysis further suggested that checking whenever new messages arrive, rather than checking at restricted intervals, is one method for reducing email overload. Jerejian et al. (2013) also found that email volume significantly predicts email stress. In contrast to the moderating effect of email strategies found by Dabbish and Kraut (2006), the relationship between email management strategies and email stress was found to be non-significant. Jerejian et al. (2013) concluded that the moderating effect of email management strategies in the relationship between email volume and email stress was not supported by their research. One of the hypotheses of this study investigates this relationship in more detail; it proposes that users will experience stress and overload because of email.

An opposing view is raised by Kushlev and Dunn (2015), who found that limiting the number of times people check their email during the day lessened tension during a particular important activity and lowered overall day-to-day stress. This is supported by a multitude of popular publications and blogs (e.g. Ashton 2015; Bradberry 2016; Pearce 2014), which advise that restricting email access to set timeslots contributes to effective time management.

\section{Email response pressure}

The almost immediate delivery of messages has created a response expectation or pressure in the minds of the communicators. A response time much closer to synchronous media is expected (Renaud et al. 2006), even though the growth in volume of email has made it almost impossible to respond to all messages immediately. According to Renaud et al. (2006), the recipient will feel pressure to respond speedily to the request or execute the task without delay, if the sender has authority over the recipient. The response time is also affected by prior experience of the sender and the recipient's opinion of the sender.

\section{Email interruptions}

Renaud et al. (2006) noted the strange anomaly that people want to be interrupted even though they know that interruptions will probably make them feel overloaded. They found that their survey respondents did not perceive the disruptive potential of email to be anything as high as traditional synchronous communication mediums (like telephone calls). They propose that the benign view of the disruptive influence of email can be because of the perceptions of control over email that respondents expressed. 
Adler and Benbunan-Fich (2013) investigated selfinterruptions (such as checking messages) in discretionary multitasking. Multitasking was defined as interleaving independent tasks in the same time period and switching among them. Interspersing among different tasks contributes to the illusion of productivity, but studies show that performance degrades when attention is divided, particularly during complex tasks (Bailey \& Konstan [2006]; Speier, Vessey \& Valacich 2003 in Adler \& Benbunan-Fich [2013]).

It is clear that communication is playing an increasingly important role in projects and project success. The transformation of communication because of the arrival of new electronic communication media formats is noted, but the impact it has on organisations is unclear. The growing use of email as a preferred communication medium in the workplace and in project environments is noted by practitioners and academics; however, its impact on individual and project performance is not clearly understood. Scholars are still trying to pin down the characteristics of email within previously accepted communication media frameworks. In the process, previously held beliefs about communication in the workplace are being challenged.

This study explores communication preferences, describes how individuals manage their email and gauges the impact of email communication on individuals, their relationships, efficiency and effectiveness in the project environment. Six hypotheses are proposed:

H1: Email is replacing other types of media in the project management environment.

H2: Email is disruptive.

H3: Users experience stress and overload because of email.

H4: Email is an effective tool to delegate tasks.

H5: Email supports building relationships and trust.

H6: Email creates conflict.

The study goes some way in providing insight into the communication preferences of project practitioners. Furthermore, the findings regarding the use of email communication in projects will assist project managers and team members to better understand the role of communication in the project and the impact of email communication on individuals and their relationships in the project environment.

\section{Conceptual model}

There are various opinions on how project success can be defined and what measures should be used to qualify as a successful project (Cooke-Davies 2002; Cserháti \& Szabó 2014; Fortune \& White 2006; Ngai et al. 2008; Pinto \& Slevin 1988). From the literature review, it is clear that there is a relationship between project communication and project success, irrespective of which definition of project success is used. Successful project communication should therefore contribute to a successful project and several aspects can contribute to successful project communication. This study investigates a number of both contributing and detracting project success factors, within the context of email project communication. It is proposed that an increase in the use of appropriate communication media, communication efficiency, effectiveness, accuracy and trust will improve project communication and thereby project success. Similarly, an increase in overload and stress, disruption and conflict will result in a decrease in project communication success.

\section{Research method and design Research strategy}

In this study, a post-positivist perspective was taken as described by Tashakkori and Teddlie (2009). These academics see post-positivism as 'currently the predominant philosophy for quantitative research in the human sciences'. Post-positivism 'assumes that the world is mainly driven by generalisable (natural) laws, but that their application and results are often situation dependent'. Postpositivist researchers therefore identify trends, that is, theories which hold in certain situations, but cannot be generalised (Biedenbach \& Müller 2011 in Joslin \& Müller [2015]). Tashakkori and Teddlie (2009) suggest that either quantitatively oriented experimental or survey research be used to assess relationships among variables and to explain those relationships statistically.

This study uses a deductive approach and cross-sectional questionnaire to test the following six hypotheses: (1) email is replacing other types of media in the project management environment; (2) email is disruptive; (3) users experience stress and overload because of email; (4) email is an effective tool to delegate tasks; (5) email supports building relationships and trust; and (6) email creates conflict. Purposive and selfselection sampling was used to conduct the web-based survey. It was important that the right sample group receives the email and self-selected sampling was used so that respondents that are familiar with the research topic respond.

\section{Research instruments}

A questionnaire was developed based on questions relating to the hypotheses and the underpinning literature. Two types of questions were used: ranking questions where respondents were asked to rank different types of communication media in order of communication medium preference for different situations and questions where respondents had to indicate their level of agreement with statements. A four-point Likert scale was used for the latter with the following levels: 1 - strongly disagree; 2 - disagree; 3 - agree; and 4 - strongly agree.

\section{Data collection}

The questionnaire was distributed in two separate campaigns. In the first campaign, email invitations to participate in the survey were sent to project practitioners and all current students and alumni of masters' projects and engineering management programmes in the Graduate School of 
Technology Management at the University of Pretoria. One hundred and thirty responses were obtained during this first campaign.

The second campaign made use of an external consultancy that specialises in assisting researchers to obtain survey responses. The company distributed the survey to individuals of their project management database. The survey was closed after 300 responses were received.

In total, 430 responses were received. A small number of responses were not complete, possibly because of connectivity issues while respondents were completing the survey. Incomplete surveys were accepted. The response rate could not be calculated as the population that received the invitation is not known.

\section{Data analysis}

Questions were grouped according to the different hypotheses. An average rank was calculated for the ranking questions and the frequency of responses for the specific group of questions compiled. The valid dataset was analysed using IBM SPSS Statistics 22.

\section{Results \\ Hypotheses testing}

\section{H1: Email is replacing other types of communication media in the project environment}

Face-to-face communication was selected as the respondents' first preference across a range of questions, with an average rank of 1.80 . This was followed by email (2.28), telephone calls (2.47), text messages (4.01) and written notes (4.44), where 1 was strongly agree and 4 strongly disagree.

Respondents indicated a preference for frequent informal feedback rather than formal progress reports $(63.5 \%$ vs. $36.5 \%)$. They placed slightly more trust in the information contained in formal reports than email (53.3\% vs. $46.7 \%$ agreeing with the statement), but substantially less trust in telephone calls compared with email (only 18.7\% agreeing).

Four Likert scale questions were posed in the survey to address this hypothesis. The highest response frequency was at 2.5 (33.4\% of responses). The average response was 2.6 , with a maximum of 4 . The highest response frequency and average response indicate a response between agreeing and disagreeing with the hypothesis. It can, therefore, not be strongly concluded that email is replacing other types of communication media in the project environment.

\section{H2: Email is disruptive}

Four Likert scale questions were posed in the survey to address this hypothesis. The highest response frequency was at 3 out of a maximum of 4 , where 1 was strongly agree and 4 strongly disagree. It can be concluded that email is disruptive.

\section{H3: Users experience stress and overload because of email}

Six Likert scale questions addressed this hypothesis in the survey. The highest response frequency was at 3 out of a maximum of 4 . It can be concluded that users experience stress and overload because of email.

\section{H4: Email is an effective tool to delegate tasks}

Face-to-face communication is the first preference of respondents, across the range of questions asked, with an average rank of 1.96. This preference is closely followed by email with 2.00, telephone calls with 2.52, text messages with 4.05 and written notes with 4.46. Four Likert scale questions were asked in the survey to address this hypothesis. The highest response frequency was at 3 out of a maximum of 4 . The average response was 3.0, where 1 was strongly agree and 4 strongly disagree. It can be concluded that email is an effective tool to delegate tasks.

\section{H5: Email communication supports building relationships and trust}

Six Likert scale questions were asked to test for conflict emanating from email. The highest response frequency was at 3 . The average response was 2.9. It can be concluded that email communication supports building relationships and trust.

\section{H6: Email creates conflict}

Four questions testing the ability to build and develop relationships and trust via email were asked. The highest response frequency was at 3 (out of a maximum of 4). The average response was 2.9. It can be concluded that email creates conflict.

\section{Ethical consideration}

The study was conducted in accordance with relevant national and international guidelines. Approval for all protocols followed in this study was obtained from the Research Ethics Committee of the University of Pretoria under permit number EBIT/GSTM/138/2016.

\section{Trustworthiness}

The study and all its findings are based on the respondents' perceptions regarding the subject matter and questions asked in the survey. Reliability was aided by a relatively large number (430) of responses received. Validity and reliability concerns were addressed in the study by utilising the services of a statistician for questionnaire design and data analysis. Key concepts and terms were defined upfront in the questionnaire so that all participants had a similar understanding of the topics being investigated. Furthermore, only close-ended questions were asked to reduce ambiguity and emotive responses. 


\section{Discussion}

\section{Communication medium preferences}

Respondents indicated that face-to-face communication is their preferred communication medium for initial communication regarding project surprises (issues). This was followed by telephone calls with messages in the third place. Respondents preferred that further follow-ups be done either through face-to-face communication or by email (equal response frequency). Based on media richness theory, it can be assumed that face-to-face communication is preferred because of the nature of the message requiring high equivocality. This would also explain why telephone calls were indicated as the second highest preference. The use of email as a joint first choice for elaborating on the initial communication can be ascribed to the fact that email leaves a 'paper trail' for future reference, but also grants the author of the email the opportunity to construct his thoughts and explain the situation on his terms, without interruption.

This study found that, despite the convenience and prevalence of email, respondents appear to have an inherent understanding of the need for communication media richness when dealing with communication requiring high equivocality. Face-to-face communication was the preferred communication medium when dealing with minor and major disagreements and conflict. Email was the first preference only for the low equivocality task of requesting information from others. These findings support the work conducted by Robert and Dennis (2005). The majority of respondents selected email above telephone calls for general and dayto-day project communication. A fear expressed by the authors that people will use email for tasks for which it is not suited is therefore mostly unfounded. However, a significant number of respondents indicated a preference for email when dealing with major disagreements (23 respondents), conflict (34 respondents) and surprises ( 80 respondents). The potential risk of ineffective communication under these circumstances cannot be ignored.

The study reported higher email volumes for senior managers. It is not clear whether this is a function of the higher communication volumes associated with management responsibilities or whether it is in conflict with the media richness theory. Email appears to be replacing telephonic communication because of the fairly narrow gap in preference between the two media for situations requiring richer media, although email does not yet exceed it.

\section{Email disruption}

Email is perceived as being a very disruptive communication method especially when visual and audible notifications inform you of every email as it is received. Of the respondents, $74 \%$ indicated that they have either a visual or audible notification that informs them of new messages arriving. The majority of respondents are, therefore, constantly aware of new messages arriving.
More than half of the respondents (55.3\%) indicated that they tend to interrupt activities to read or respond to email. An almost similar percentage $(54.4 \%)$ indicated that excessive email prevents them from structuring their day and executing tasks according to their own daily schedule. The number of respondents agreeing with the statement that excessive email queries prevent them from structuring their day and executing tasks according to their own daily schedule increased with an increase in email volume.

\section{Email overload and stress}

A large source of stress at work originates from information overload, and more specifically email overload (Bawden \& Robinson 2009; Gantz et al. 2009; Sappelli et al. 2016). However, the findings of this study showed that $82.3 \%$ of respondents indicated they are able to cope with current volume of email that they receive and therefore do not deem themselves to be overloaded because of email. In general, the findings support the statement that higher email volume was associated with increased feelings of email overload.

More than half of the respondents agreed that email is a contributor to stress at work. This increased with the number of messages received, with recipients of more email indicating higher levels of stress associated with email. This finding supports the research conducted by Jerejian et al. (2013).

\section{Email response pressure}

In total, $88.2 \%$ of respondents indicated that they respond to messages as quickly as possible to prevent messages from piling up in their inbox. It was interesting to note that the majority of the respondents $(61.9 \%)$ agreed that the seniority of the sender is a significant determinant in the response time. The recipient's opinion of the sender was found to have limited influence on the speed of response.

\section{Email and delegation of tasks}

Email was found to be an easy and effective tool to request information, make demands and delegate tasks. It was the second most preferred communication medium for delegating tasks after face to-face communication (average rank 1.99 vs. 1.77 for face-to-face communication). The delegation of tasks did not result in abdication of ownership of the problem, despite requesting others for assistance or information regarding the problem.

\section{Email and relationships}

The majority of respondents indicated that they can build new work relationships with project members via email $(60.3 \%)$. Even a greater proportion of the respondents (85.8\%) agreed that they can maintain existing work relationships with project team members via email. Both these findings contribute to the work conducted by Cheshin et al. (2013). It was not tested whether email is exclusively used for communication in these instances, but it would appear as if respondents are comfortable to use email as a tool to develop and maintain relationships. 


\section{Email and conflict}

Email can be manipulated to manage the flow of information by selecting the email recipients carefully. In total, $68.5 \%$ of respondents indicated that they exclude certain individuals from the distribution list to prevent negative consequences stemming from the contents of the email. The selective distributions lists can result in conflict, with $80.9 \%$ of respondents indicating that email creates conflict when they are excluded from email distribution lists on subjects that involve them. In addition, $64.7 \%$ of respondents agreed that email creates conflict when the sender and recipient's superior is copied in on messages.

The respondents were evenly divided regarding the need to follow up on messages to resolve misunderstandings arising from the original message and, as such, the risk of an ambiguous and poorly written message resulting in conflict did not materially realise. However, the tone of messages was found to have a much greater propensity to cause conflict; $80.4 \%$ of respondents indicated that conflict is created because of the tone of the email that some recipients deem to be offensive. Despite the confirmation that email causes conflict, this did not impact the ability to build and maintain relationships via email. The finding that the tone of an email can create conflict supports the research conducted by Turner and Müller (2004) and Bond-Barnard et al. (2013), which state that conflict can only be reduced by having a balance of informal and formal communication. A balance of communication types would assist the parties to address any issues face-to-face that may stem from formal, written communication such as an email.

\section{Email and trust}

Respondents indicated a slightly higher level of trust for information contained in formal reports when compared with information provided in an email, this aligns with Turner and Müller (2004). A significantly higher level of trust is placed in the accuracy of information contained in messages when compared with telephone calls. This can possibly be ascribed to the fact that messages produce a communication trail that can be accessed in the case of a dispute, whereas telephone calls are rarely recorded.

In total, $65.4 \%$ of respondents indicated that project communication by email increases the level of trust between the respondent and project team members. Respondents overwhelmingly agreed that email facilitates collaboration between them and the project team. Despite this, 92.3\% of respondents indicated that they archive the majority of their mail as evidence in case of future disputes.

\section{Email efficiency and effectiveness}

Responses supported the notion that email is an efficient communication medium, with more than $85 \%$ of respondents indicating that email allows them to efficiently perform their duties, irrespective of the number of messages they receive each day. This percentage was independent of the number of messages received daily for the respondents receiving less than 25 messages per day, between 25 and 49 and between 50 and 74 messages per day $(88.8 \%, 85.3 \%$ and $87.1 \%)$.

\section{The contribution of email to project success}

The vast majority of respondents indicated that email contributes more to successful project execution and success than hampering it $(91.6 \%)$.

\section{Limitations of the study}

The study did not consider the age or computer literacy of respondents. Both these factors could potentially impact the participant's perception and preferences regarding email.

The survey made use of convenience sampling. The industries in which the respondents are working in were not surveyed, and a potential relationship between industry and responses was not investigated. The localities of respondents are not certain, although it can be assumed that the majority of the respondents are based in South Africa, and the results can therefore not necessarily be extrapolated to other countries or regions.

The study focused on communication preferences but did not measure actual experience of which communication media were used for the different situations.

\section{Conclusion}

The last two decades have witnessed an unprecedented shift in project communication from face-to-face conversations to email, short message service (SMS), instant messaging and video conferencing. The aim of this study was to assess current communication preferences of project practitioners to determine if and how these preferences have changed in comparison with literature from 20 years ago. The following hypotheses were tested in the study in order to address the aim of the study: (1) email is replacing other types of media in the project management environment; (2) email is disruptive; (3) users experience stress and overload because of email; (4) email is an effective tool to delegate tasks; (5) email supports building relationships and trust and (6) email creates conflict. The study found that communication media higher in richness than email are still preferred for most situations, especially for communication requiring higher equivocality. This supports the media richness theory. The findings indicate that email has replaced telephonic communication only for general communication, which is low in equivocality. Respondents also place more trust in information contained in messages than telephone calls.

The study found that email is indeed disruptive, but the majority of respondents allow themselves to be disrupted by using email notifications and also electing to disrupt other activities to read and respond to messages.

Email is a cause of stress in the workplace, and higher levels of stress are correlated with an increase in the number of email messages received. However, the majority of 
respondents indicated that they can cope with the number of messages that they receive and as such do not report to be overloaded by email.

Email is an effective tool to delegate work and was not found to be associated with abdication of accountability.

Email communication assists in building and maintaining project team relationships, despite agreement that email and specific uses of email can lead to conflict. Even though there was consensus that email communication creates trust, most respondents agreed that they archive the majority of their mail as evidence in case of future conflict. All the hypotheses except hypothesis 1, which states that email is replacing other types of media in the project management environment, are supported by the findings of the study.

Despite the disruptive nature of email and stress resulting from email, the respondents agreed that email contributes to task efficiency and effectiveness. The study found that email contributes more to project success than hampering it.

It is suggested that future studies should investigate whether project practitioner preferences correlate with their actual communication experiences. The demographical data did not include age, and it would be worthwhile to investigate whether a participant's perception of email, especially with regard to relationships and trust, is correlated with age.

\section{Acknowledgements Competing interests}

The authors declare that they have no financial or personal relationship(s) that may have inappropriately influenced them in writing this article.

\section{Authors' contributions}

M.C.S. conceptualised the study topic, carried out the research and wrote the first draft of the manuscript. T.J.B-B. reviewed and critiqued the paper several times. She was responsible for putting the paper in the correct journal format and acting as the corresponding author. H.S. is M.C.S.'s supervisor for his master's mini dissertation. He also reviewed and critiqued the paper several times. I.F-R. assisted with questionnaire design and was responsible for performing all statistical calculations.

\section{References}

Adler, R.F. \& Benbunan-Fich, R., 2013, 'Self-interruptions in discretionary multitasking', Computers in Human Behavior 29(4), 1441-1449. https://doi.org/10.1016/j chb.2013.01.040

Ashton, R., 2015, Email overload: How to escape the tyranny of the inbox, viewed 12 October 2016, from https://www.theguardian.com/small-businessnetwork/2015/aug/18/email-overload-escape-tyranny-inbox

Bailey, B.P. \& Konstan, J.A., 2006 , 'On the need for attention-aware systems: Measuring effects of interruption on task performance, error rate, and affective state', Computers in Human Behavior 22(4), 685-708. https://doi.org/10.1016/j. state', Computers
chb.2005.12.009
Bawden, J.D. \& Robinson, L., 2009, 'The dark side of information: Overload, anxiety and other paradoxes and pathologies', Journal of Information Science 35(2), 180-191. https://doi.org/10.1177/0165551508095781

Bond-Barnard, T.J., Steyn, H. \& Fabris-Rotelli, I., 2013, 'The impact of a call centre on communication in a programme and its projects', International Journa of Project Management 31(7), 1006-1016. https://doi.org/10.1016/j. ijproman.2012.12.012

Bond-Barnard, T.J., Fletcher, L. \& Steyn, H., 2016, 'Exploring the influence of instant messaging and video conferencing on the quality of project communication', Acta Structilia 23(1), 36-69.

Bradberry, T., 2016, 14 critical things ridiculously successful people do every day, viewed12 October 2016, from http://www.huffingtonpost.com/dr-travisbradberry/14-things-ridiculously-su_b_9760972.html

Bryde, J.D. \& Robinson, L., 2005, 'Client versus contractor perspectives on project success criteria', International Journal of Project Management 23, 622-629. https://doi.org/10.1016/j.ijproman.2005.05.003

Burgess, A., Jackson, T. \& Edwards, J., 2005, 'Email training significantly reduces email defects', International Journal of Information Management 25(1), 71-83. https:// doi.org/10.1016/j.ijinfomgt.2004.10.004

Cheshin, A., Kim, Y., Nathan, D.B., Ning, N. \& Olson, J.S., 2013, 'Emergence of differing electronic communication norms within partially distributed teams', Journal of Personnel Psychology 12, 7-21. https://doi.org/10.1027/1866-5888/a000076

Chiocchio, F., 2007, 'Project team performance: A study of electronic task and coordination communication', Project Management Journal 38(1), 97-110.

Colquitt, J.A., Hollenbeck, J.R., Ilgen, D.R., LePine, J.A. \& Sheppard, L., 2002, 'Computer-assisted communication and team decision-making performance: The moderating effect of openness to experience', Journal of Applied Psychology $87(2), 402-410$.

Cooke-Davies, T., 2002, 'The "real" success factors on projects', International Journal of Project Management 20, 185-190. https://doi.org/10.1016/S02637863(01)00067-9

Crawford, L. \& Nahmias, A.H., 2010, 'Competencies for managing change', International Journal of Project Management 25(4), 405-412. https://doi. org/10.1016/j.ijproman.2010.01.015

Cserháti, G. \& Szabó, L., 2014, 'The relationship between success criteria and success factors in organisational event projects', International Journal of Project Management 32(4), 613-624. https://doi.org/10.1016/j.ijproman.2013.08.008

Dabbish, L.A. \& Kraut, R.E., 2006, 'Email overload at work: An analysis of factors associated with email strain', In Computer Supported Cooperative Work '06, Banff, Alberta, Canada, pp. 431-440. https://doi.org/10.1145/1180875.1180941

Den Otter, A. \& Emmitt, S., 2007, 'Exploring effectiveness of team communication: Balancing synchronous and asynchronous communication in design teams', Engineering, Construction and Architectural Management 14(5), 408-419. Engineering, Construction and Architectura
https://doi.org/10.1108/09699980710780728

Dredze, M., Blitzer, J. \& Pereira, F., 2005, 'Reply expectation prediction for email management', in 2nd Conference on Email and Anti-Spam, pp. 2-3, Citeseer, Stanford, CA.

Elovitz, K.M., 1999, Cultivating communication: A must, Consulting-Specifying Engineer, Denver, CO

Fortune, J. \& White, D., 2006, 'Framing of project critical success factors by a systems model', International Journal of Project Management 24(1), 53-65. https://doi. org/10.1016/j.ijproman.2005.07.004

Frodell, M., Josephson, P.E. \& Lindahl, G., 2008, 'Swedish construction clients' views on project success and measuring performance', Journal of Engineering, Design and Technology 6, 21-32. https://doi.org/10.1108/17260530810863316

Gantz, J., Boyd, A. \& Dowling, S., 2009, Cutting the clutter: Tackling information overload at the source, International Data Corporation White Paper.

Henderson, L.S., Stackman, R.W. \& Lindekilde, R., 2016, 'The centrality of communication norm alignment, role clarity, and trust in global project teams', International Journal of Project Management 34(8), 1717-1730. https://doi. International Journal of Project Mand
org/10.1016/j.ijproman.2016.09.012

Jerejian, A.C.M., Reid, C. \& Rees, C.S., 2013, 'The contribution of email volume, email management strategies and propensity to worry in predicting email stress among academics', Computers in Human Behavior 29(3), 991-996. https://doi. org/10.1016/j.chb.2012.12.037

Joslin, R. \& Müller, R., 2015, 'Relationships between a project management methodology and project success in different project governance contexts', International Journal of Project Management 33(6), 1377-1392. https://doi. org/10.1016/j.jijproman.2015.03.005

Kahai, S.S., Sosik, J.J. \& Avolio, B.J., 2004, 'Effects of participative and directive leadership in electronic groups', Group \& Organization Management 29(1), 67-105.

Koops, L., Bosch-Rekveldt, M., Coman, L., Hertogh, M. \& Bakker, H., 2016, 'Identifying perspectives of public project managers on project success: Comparing viewpoints of managers from five countries in North-West Europe', JPMA 34(5), 874-889. https://doi.org/10.1016/j.ijproman.2016.03.007

Ksenija, Č. \& Skendrovic, V., 2010, 'Communication management is critical for project success', Informatol 43(3), 228-235.

Kushlev, K. \& Dunn, E.W., 2015, 'Checking email less frequently reduces stress', Computers in Human Behavior 43, 220-228. https://doi.org/10.1016/j. chb.2014.11.005

Lehmann, V., 2009, Communication and project management: Seeds for a new conceptual approach, Administrative Sciences Association of Canada, Niagara Falls, Ontario. 
Lim, C.S. \& Mohamed, M.Z., 1999, 'Criteria of project success: An exploratory re-examination' International Journal of Project Management 17(4), 243-248. https://doi.org/10.1016/S0263-7863(98)00040-4

Markus, M.L., 1994, 'Electronic mail as the medium of managerial choice', Organization Science 5(4), 502-527. https://doi.org/10.1287/orsc.5.4.502

McLeod, L., Doolin, B. \& MacDonell, S.G., 2012, 'A perspective-based understanding of project success', Project Management Journal 43, 68-86. https://doi. org/10.1002/pmj.21290

Michinov, N., Michinov, E. \& Toczek-Capelle, M.-C., 2004, 'Social identity, group processes, and performance in synchronous computer-mediated communication', Group Dynamics 8(1), 27-39.

Mintzberg, H., 1973, The nature of managerial work, New Harper \& Row, New York.

Müller, R., 2003, Communication of information technology project sponsors and managers in buyer-seller relationships, Brunel University, Henley-on-Thames, UK.

Müller, R. \& Turner, J.R., 2001, 'The impact of performance in project management knowledge areas on earned value results in information technology projects', International Journal of Project Management 7(1), 44-50.

Ngai, E.W., Law, C.C. \& Wat, F.K., 2008, 'Examining the critical success factors in the adoption of enterprise resource planning', Computers in Industry 59(6), 548-564. https://doi.org/10.1016/j.compind.2007.12.001

Padalkar, M. \& Gopinath, S., 2016, 'Six decades of project management research: Thematic trends and future opportunities', International Journal of Project Management 34(7), 1305-1321. https://doi.org/10.1016/j.ijproman. 2016.06.006

Pearce, R., 2014, 8 ways to reduce email overload, viewed 25 October 2016, from http://www.pressreader.com/new-zealand/nz-business/20140501/28159 9533487907

Pinto, J. \& Slevin, D., 1988, 'Critical success factors across the project life cycle', Project Management Journal 19(3), 67-75.

Pinto, J.K. \& Slevin, D.P., 1987, 'Critical success factors in effective project implementation', IEEE Transactions on Engineering Management EM34, 22-28.
PwC South Africa, 2017, Chapter 5: The governance of information technology, viewed 05 February 2017, from http://www.pwc.co.za/en/king3/the-governance-ofinformation-technology.html

Ramsay, J. \& Renaud, K., 2012, 'Using insights from email users to inform organisational email management policy', Behaviour \& Information Technology 31(6), 587-603. https://doi.org/10.1080/0144929X.2010.517271

Renaud, K., Ramsay, J. \& Hair, M., 2006, 'You've got email. Shall I deal with it now? Electronic mail from the recipient's perspective', International Journal of Human-Computer Interaction 21(3), 313-332. https://doi.org/10.1207/ s15327590ijhc2103_3

Robert, L.P. \& Dennis, A.R., 2005, 'Paradox of richness: A cognitive model of media choice', IEEE Transactions on Professional Communication 48(1), 10-21. https:// doi.org/10.1109/TPC.2004.843292

Sappelli, M., Pasi, G., Verberne, S., De Boer, M. \& Kraaij, W., 2016, 'Assessing e-mail intent and tasks in e-mail messages', Information Sciences 358-359, 1-17. https:// doi.org/10.1016/j.ins.2016.03.002

Sumecki, D., Chipulu, M. \& Ojiako, U., 2011, 'Email overload: Exploring the moderating role of the perception of email as a "business critical" tool', International Journal of Information Management 31(5), 407-414. https://doi.org/10.1016/j. of Information Mamgt.2010.12.008

Tashakkori, A. \& Teddlie, C., 2009, Foundations of mixed methods research. Integrating quantitative and qualitative, SAGE Publications Inc., Thousand Oaks, CA.

Turner, J.R., 2007, Gower handbook of project management, 4th edn., Gower, Aldershot.

Turner, J.R. \& Müller, R., 2004, 'Communication and co-operation on projects between the project owner as principal and the project manager as agent', European Management Journal 22(3), 327-336. https://doi.org/10.1016/j. emj.2004.04.010

Wilson, E.V., 2002, 'Email winners and losers', Communications of the ACM 45(10), 121-126. https://doi.org/10.1145/570907.570908 